\title{
Properties and Corrosion Performance of Self-reinforced Composite PEEK for Proposed Use as a Modular Taper Gasket
}

\author{
Eric S. Ouellette BS, Jeremy L. Gilbert PhD
}

Published online: 4 May 2016

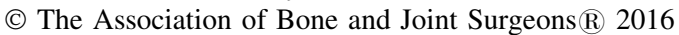

\begin{abstract}
Background Fretting corrosion in medical alloys is a persistent problem, and the need for biomaterials that can effectively suppress mechanically assisted crevice corrosion in modular taper junctions or otherwise insulate metalon-metal interfaces in mechanically demanding environments is as yet unmet.

Questions/purposes The purpose of this study is to characterize a novel material, self-reinforced composite polyetheretherketone (SRC-PEEK) and to evaluate its ability to inhibit fretting corrosion in a pin-on-disk metalon-metal interface test.
\end{abstract}

One of the authors (JLG) consults for DePuy Synthes (Warsaw, IN, USA), Stryker Orthopedics (Mahwah, NJ, USA), ZimmerBiomet (Warsaw, IN, USA), Medtronic (Memphis, TN, USA), Bayer (Whippany, NJ, USA), and Corin (Cirencester, Gloucestershire, UK). Syracuse University receives research contract support (JLG,

Principal Investigator) from DePuy Synthes and Stryker. One of the authors (JLG) is Editor-in-Chief of the Journal of Biomedical Materials Research-Part B: Applied Biomaterials and serves on the Council of the Society for Biomaterials. One of the authors certifies that he (JLG), or a member of his or her immediate family, has or may receive payments or benefits, during the study period, an amount of USD 100,001 to USD 1,000,000, from DePuy Synthes, USD 10,000 to USD 100,000 from Stryker Orthopedics, USD 10,000 to USD 100,000 from ZimmerBiomet, less than USD 10,000 from Medtronic, less than USD 10,000 from Corin, and less than USD 10,000 from Bayer.

All ICMJE Conflict of Interest Forms for authors and Clinical Orthopaedics and Related Research ${ }^{\mathbb{R}}$ editors and board members are on file with the publication and can be viewed on request. Clinical Orthopaedics and Related Research ${ }^{\circledR}$ neither advocates nor endorses the use of any treatment, drug, or device. Readers are encouraged to always seek additional information, including FDAapproval status, of any drug or device prior to clinical use.

This work was performed at Syracuse University, Syracuse, NY, USA.
Methods SRC-PEEK was fabricated by hot compaction of in-house-made PEEK fibers by compacting uniaxial layups at $344^{\circ} \mathrm{C}$ under a load of $18,000 \mathrm{~N}$ for 10 minutes. SRC-PEEK, bulk isotropic PEEK, and the in-house-made PEEK fibers were analyzed for thermal transitions $\left(T_{g}, T_{m}\right)$ through differential scanning calorimetry, crystallinity, crystal size, crystalline orientation (Hermanns orientation parameter) through wide-angle $\mathrm{x}$-ray scattering, and modulus, tensile strength, yield stress, and strain to failure through monotonic tensile testing. SRC-insulated pin-ondisk samples were compared with metal-on-metal control samples in pin-on-disk fretting corrosion experiments using fretting current and fretting mechanics measurements. Fifty-micron cyclic motion at $2.5 \mathrm{~Hz}$ was applied to the interface, first over a range of loads $(0.5-35 \mathrm{~N})$ while held at $-0.05 \mathrm{~V}$ versus $\mathrm{Ag} / \mathrm{AgCl}$ and then over a range of voltages $(-0.5$ to $0.5 \mathrm{~V})$ at a constant contact stress of $73 \pm$ $19 \mathrm{MPa}$ for SRC-PEEK and $209 \pm 41 \mathrm{MPa}$ for metal-onmetal, which were different for each group as a result of changes in true contact area due to variations in modulus between sample groups. Pins, disks, and SRC samples were imaged for damage (on alloy and SRC surfaces) and evidence of corrosion (on alloy pin and disk surfaces). SRC specimens were analyzed for traces of alloy transferred to the surface using energy dispersive spectroscopy after pinon-disk testing.

\section{E. S. Ouellette, J. L. Gilbert}

Department of Biomedical and Chemical Engineering, Syracuse University, Syracuse, NY, USA

\section{E. S. Ouellette, J. L. Gilbert ( $\square$ )}

Syracuse Biomaterials Institute, 318 Bowne Hall, Syracuse, NY 13244, USA

e-mail: gilbert@syr.edu 
Results SRC-PEEK showed improved mechanical properties to bulk PEEK (modulus $=5.0 \pm 0.3 \mathrm{GPa}, 2.8 \pm 0.1$ GPa, respectively, $\mathrm{p}<0.001)$ and higher crystallinity to bulk PEEK $(44.2 \% \pm 3 \%, 39.5 \% \pm 0.5 \%$, respectively, $\mathrm{p}=$ 0.039), but had comparable crystalline orientation as compared with the initial PEEK fibers. SRC-PEEK reduced fretting currents compared with metal-on-metal controls by two to three orders of magnitude in both variable load $(4.0 \mathrm{E}-5 \pm 3.8 \mathrm{E}-5 \mu \mathrm{A}$ versus $2.9 \mathrm{E}-3 \pm 7.1 \mathrm{E}-4 \mu \mathrm{A}$, respectively, $\mathrm{p}=0.018)$ and variable potential $(7.5 \mathrm{E}-6 \pm$ $4.7 \mathrm{E}-6 \mu \mathrm{A}$ versus $5.3 \mathrm{E}-3 \pm 1.4 \mathrm{E}-3 \mu \mathrm{A}$, respectively, $\mathrm{p}=$ 0.022 ) fretting corrosion testing. Minimal damage was observed on surfaces insulated with SRC-PEEK, whereas control surfaces showed considerable fretting corrosion damage and metal transfer.

Conclusions The SRC-PEEK gaskets in this study demonstrated higher crystallinity and crystalline orientation and improved monotonic tensile properties compared with bulk PEEK with the ability to effectively insulate Ti6Al4V and CoCrMo alloy surfaces and prevent the initiation of fretting corrosion under high contact-stress conditions.

Clinical Relevance This novel SRC-PEEK material may offer potential as a thin film gasket material for modular tapers. Pending further in vitro and in vivo analyses, this approach may be able to preserve the advantages of modular junctions for surgeons while potentially limiting the downside risks associated with mechanically assisted crevice corrosion.

\section{Introduction}

Fretting corrosion, or mechanically assisted crevice corrosion (MACC), of modular tapers is a well-documented process by which damage of the implant may lead to corrosion and wear debris that may cause a negative biological response in some patients including increased serum ion levels, pseudotumor formation, aseptic loosening, and others [7, 8, 27]. Many efforts have been made to document in vivo evidence of fretting corrosion through retrieval studies aimed at a better understanding of the mechanisms through which it occurs and the conditions that may lead to its initiation [3, 6, 11, 12, 15, 18, 23, 27]. Furthermore, in vitro models to understand the performance of tapers in a simulated physiologic situation have been developed, and there are multiple reports linking cyclic loading of headneck tapers to the generation of corrosion currents in these models [13, 14, 20].

Whereas the orthopedic community recognizes MACC at modular interfaces as a concern, it also must be recognized that modularity in joint replacement is an important design feature that allows for placement of the optimum materials in certain locations, may allow for better restoration of anatomy, and may allow for easier revision should an implant fail. These are benefits that cannot be overlooked, and as such, efforts are being focused on further understanding and ultimately on preventing fretting corrosion phenomena at the modular taper interface.

Recent studies on fretting corrosion have been conducted using a custom-built pin-on-disk apparatus designed to capture electrochemical data concurrently with information about the sliding mechanics taking place at the interface $[4,5,25,26]$. This has resulted in the ability to correlate the rise and fall of currents with the abrasive processes at the interface resulting from small-scale cyclic motion and therefore provides the ability to understand the time, mechanical, and diffusion-dependent processes that affect mechanically assisted crevice corrosion.

There have been relatively few reports on possible design or biomaterials innovation-based solutions to MACC processes at modular tapers. Potential methods to solve this mechanism include limiting the ingress of solution into the taper junction, limiting the contact of hard-on-hard surface contacts that give rise to the fretting corrosion damage, and/ or creating an insulating layer between the two metal-onmetal surfaces to limit electrical connectivity, which is a requirement for corrosion interactions. The contact stresses within a modular taper junction are also an element that requires biomaterials that can withstand the high stress state resulting from seating and loading during daily activity without wearing out or becoming damaged. One potential candidate biomaterial is self-reinforced composite polyetheretherketone (SRC-PEEK) which is a PEEK fiberbased composite whose matrix comes from hot compaction of the fibers under high pressure [16, 17, 22, 24, 28, 29]. This high-temperature semicrystalline polymer, when fabricated into an SRC-PEEK thin-film gasket, may be suitable as an interpositional material for the modular junction to meet the previously described requirements.

Therefore, the purpose of this study was to evaluate a newly developed composite material, SRC-PEEK, for use in thin-film gaskets to be used in the modular taper of joint prostheses. In particular, differences in thermal, microstructural, and mechanical properties of SRC-PEEK as compared with bulk isotropic PEEK and the PEEK fibers from which it was created were explored, because these properties may influence the ability of such a material to withstand the stresses and abrasive conditions present in modular taper junctions. The electrochemical and mechanical performance of metal-on-metal couples that have been insulated with samples of SRC-PEEK was evaluated through pin-on-disk fretting corrosion studies. Finally, the damage incurred on SRC-PEEK and alloy surfaces during short-term pin-on-disk testing was documented to gain insight into the potential ability of SRC- 
PEEK to prevent fretting corrosion over a long period the rigorous mechanical environment that exists in the modular taper.

\section{Materials and Methods}

\section{Sample Preparation}

SRC-PEEK was produced using the well-known process of hot compaction, whereby polymeric fibers are sintered under elevated temperature and pressure over a short time period, allowing for the melting and recrystallization of only the surface of the fiber to form a coherent recrystallized matrix surrounding the remaining fiber fraction to act as the reinforcing phase. SRC-PEEK was fabricated in the following manner: previously characterized PEEK fibers [21] (spun inhouse from Evonik Vestakeep 4000G precursor polymer [Evonik Degussa, Essen, Germany]) with an average fiber diameter of $47 \mu \mathrm{m}$ were uniaxially arranged with a nominal thickness of two to three fibers in a rectangular channel mold preheated to the process temperature (Fig. 1). The mold was then set in a hydraulic heated press (Carver, Wabash, IN, USA), held to a constant load of 18,000 N (approximately 2.6 $\mathrm{MPa}$ ) to apply light constraint to the fibers during compaction, and as near a constant $344^{\circ} \mathrm{C}$ as possible given equipment constraints for a total of 10 minutes. These parameters had resulted in coherent film samples in preliminary studies and were based on work performed on other materials $[24,30]$. The sample was allowed to cool slowly to below the glass transition temperature $\left(\mathrm{T}_{\mathrm{g}}, 150^{\circ} \mathrm{C}\right)$ before removal from the compaction mold. The resulting SRC-

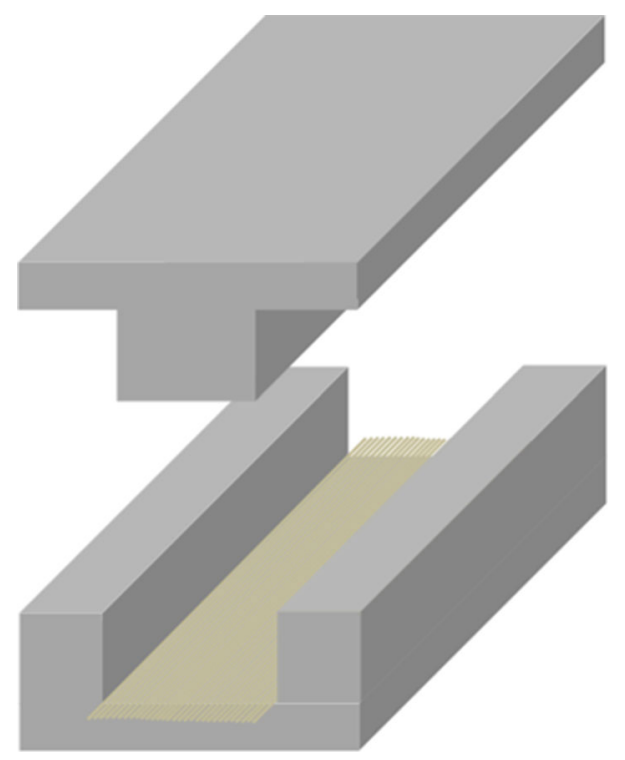

Fig. 1 This is a schematic showing fibers as they are laid up in the compaction channel mold.
PEEK samples, although not rigorously studied for thickness, were approximately $110 \mu \mathrm{m}$ thick, in general agreement with the method for laying up fibers with an approximate thickness of two to three fiber diameters and therefore as thin as possible. SRC-PEEK samples produced in this manner were used in all material characterizations and experiments described henceforth.

\section{Differential Scanning Calorimetry}

Differential scanning calorimetry (DSC; TA Instruments, Newcastle, DE, USA) was performed on SRC-PEEK, PEEK fibers, and bulk PEEK to assess differences in $T_{g}$ and $T_{m}$ as well as infer possible differences in crystallinity or crystal size/morphology among the composite sample, the fibers from which it was processed, and the isotropic bulk material from which the fibers were spun $(n=3$ samples for all groups). Samples were heated from ambient to $380^{\circ} \mathrm{C}$ (for PEEK, $\mathrm{T}_{\mathrm{m}} \approx 345^{\circ} \mathrm{C}$ ) at $10^{\circ} \mathrm{C} / \mathrm{min}$, held for 2 minutes, cooled to ambient at $10^{\circ} \mathrm{C} / \mathrm{min}$, and heated and cooled under the same conditions once more. For bulk PEEK samples, second heating scans were presented, and for SRC-PEEK and PEEK fibers, first heating scans were presented, because any preferential crystalline or amorphous orientation achieved in fiber spinning was lost on first melting and would thus differ in thermal behavior on second heating [19].

\section{Wide-angle X-ray Scattering}

Crystallinity, crystal size, and crystalline orientation were obtained from wide-angle x-ray scattering (WAXS). SRCPEEK, PEEK fiber, and bulk PEEK samples were assessed with WAXS using a copper source at $45 \mathrm{KV}$ and $0.88 \mathrm{~mA}$ for 90 minutes (Rigaku, Japan) ( $\mathrm{n}=3$ samples for all groups). Intensity versus $2 \theta$ plots were produced to allow for calculation of crystallinity and crystal size (equations 1 and 2 , respectively):

$X_{c}=\frac{\sum_{i=0}^{n} A_{i, \text { cryst }}}{\sum_{i=0}^{n} A_{i, \text { total }}}$.

The crystalline fraction of the polymer $\left(X_{c}\right.$, Eq. 1) was calculated as the sum of the area of the crystalline diffraction peaks $\left(\mathrm{A}_{\mathrm{i}}\right.$, cryst $)$ divided by the sum of the total (crystalline and amorphous) peak areas $\left(\mathrm{A}_{\mathrm{i}}\right.$, total $)$ when calculated from deconvolved WAXS diffraction data [1].

$l_{(110)}=\frac{k \lambda}{\beta \cos \theta}$.

The Scherrer equation [1] (Eq. 2) was used to determine the crystallite size, "l", with respect to some plane $(h k l)$, 
where $\kappa$ is the Scherrer parameter, $\lambda$ is the incident $\mathrm{x}$-ray wavelength, $\beta$ is the full width at half maximum of the crystalline peak, and $\theta$ is the peak location along the $2 \theta$ axis. Crystalline orientation was calculated by applying the Hermanns orientation function to an azimuthal slice of the (200) plane to calculate the orientation of crystallites with respect to the c-axis of the crystal lattice [2].

\section{Tensile Testing}

Uniaxial tensile tests were carried out on dogbone samples (with a gauge length of $6.25 \mathrm{~mm}$ ) of SRC-PEEK and bulk PEEK at a rate of $2 \mathrm{~mm} / \mathrm{min}$ on a Test Resources tensile test system (Shakopee, MN, USA) for films of SRC-PEEK and bulk PEEK ( $\mathrm{n}=3$ for all groups). Strain measurements were made from machine displacement. Data for PEEK fibers were previously published by the authors and are used for comparison to the SRC material fabricated from them [21]. Plots of engineering stress versus strain were presented for representative data from each sample group, and modulus, tensile strength, yield stress, and strain-tofailure were calculated.

\section{Pin-on-Disk Testing and Analysis}

Pin-on-disk (POD) fretting corrosion testing was used to assess the fretting corrosion behavior of common biomedical couples, namely Ti6Al4V pins and CoCrMo disks (Medtronic, Inc, Memphis, TN, USA), when undergoing fretting with contact of the two alloy surfaces or when undergoing fretting with an interpositional lining comprised of SRC-PEEK. The POD fretting system has been described extensively in previously published work $[25,26]$. SRC-PEEK samples were mounted with a Ti6Al4V pin, a CoCrMo disk, and a small piece of SRCPEEK film, approximately $3 \mathrm{~mm}$ in diameter, sandwiched between the metal couple by an applied normal force
(Fig. 2). Control samples were mounted similarly but without the small round sample of SRC-PEEK sandwiched between them. In all test cases, a Ti6Al4V pin of a small diameter $(0.5-1.0 \mathrm{~mm}$, a range which is the result of wet polishing the tip of the pin with carbide sandpaper) was fixed to a six-axis load cell (ATI; Apex, NC, USA). The true area of contact measured microscopically after testing (described subsequently) was considerably less than the nominal area of contact determined by the pin diameter, and as such the range of pin diameters was not as important to control. A CoCrMo disk was mounted in the base of an electrochemical cell, which was cyclically displaced $50 \mu \mathrm{m}$ at a rate of $2.5 \mathrm{~Hz}$ by a piezo-actuator. Both pins and disks were initially wet polished with sequentially finer carbide sandpapers, from 240 grit to a final polish with 600 grit paper to impart consistent surface roughness. In both cases, the working electrode for the three-electrode electrochemical circuit was the CoCrMo disk electrically connected to the Ti6Al4V pin, the counterelectrode used was carbon, the reference electrode was $\mathrm{Ag} / \mathrm{AgCl}$, and the electrolyte used was phosphate-buffered saline, $\mathrm{pH} 7.4$ (Sigma Aldrich, St Louis, MO, USA). For the following tests, three samples of the Ti6Al4V/SRC-PEEK/CoCrMo samples and three Ti6Al4V/CoCrMo control samples were used. For both groups, the variable load test was performed first followed immediately on the same test area by the variable potential test. Each test is described in that succession subsequently. Three pairs of pins and disks were used for each group (and three separate SRC-PEEK samples in the experimental group).

During the variable load tests, the currents were allowed to settle after fixing the voltage to $-0.05 \mathrm{~V}$ versus $\mathrm{Ag} /$ $\mathrm{AgCl}$, following which 120 seconds of fretting were performed followed by 80 seconds of rest at applied normal loads (perpendicular to the disk surface) ranging from 0.5 to $35 \mathrm{~N}$ starting at the lowest load and increasing incrementally. Loads of $0.5 \mathrm{~N}, 1 \mathrm{~N}, 2 \mathrm{~N}, 4 \mathrm{~N}, 6 \mathrm{~N}, 10 \mathrm{~N}, 15 \mathrm{~N}$, $20 \mathrm{~N}, 25 \mathrm{~N}, 30 \mathrm{~N}$, and $35 \mathrm{~N}$ were used. The smaller increment of loads at the low end of the range was chosen

Fig. 2A-B These are photographs of the fretting setup, which has been previously described by Swaminathan et al. [25]. (A) This photograph shows a side view of the POD system. (B) This photograph shows the SRC-PEEK sandwiched between the conical pin (Ti6Al4V) and flat disk (CoCrMo) in the base of the electrochemical cell.
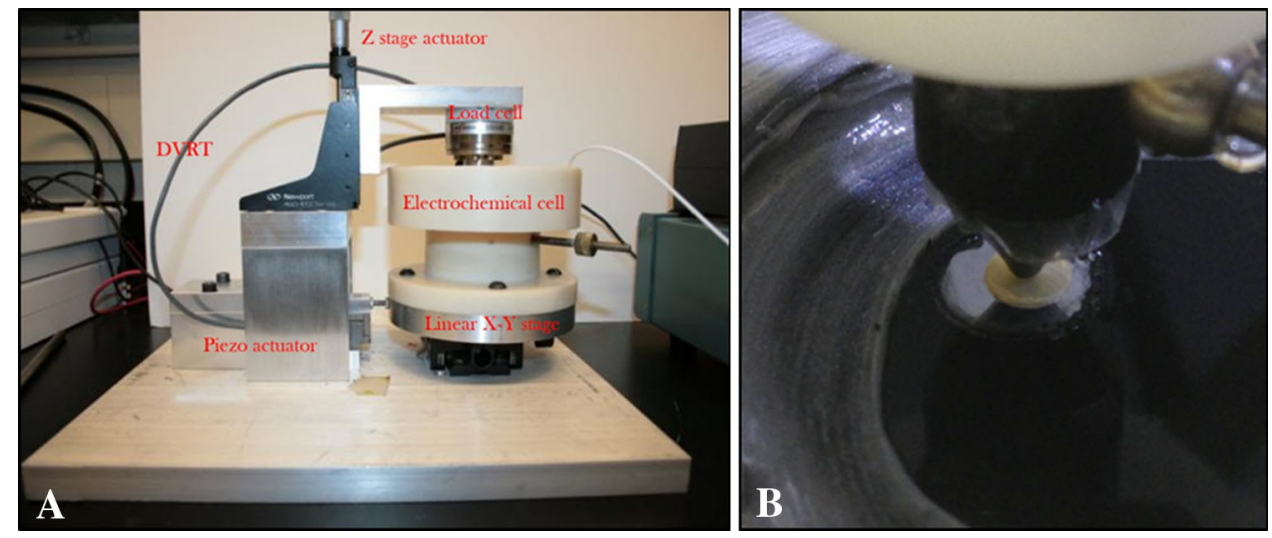
to capture any change in electrochemical or mechanical behavior as the samples came into contact and experienced more complete engagement. One hundred twenty seconds was chosen as the time interval to perform fretting because these short-term experiments are aimed at elucidating the short-term corrosion response to fretting corrosion at varied load (and therefore contact stress) rather than determining the longevity of such a material. Such experiments would be best performed in a more applied in vitro test. Current was continuously recorded, whereas mechanical data (normal load and pin displacement) were recorded for 1 second during the last 10 seconds of every fretting cycle.

Immediately after the conclusion of the variable load test, a variable potential test was performed, where the normal load (and thus, the resulting nominal contact stress) was held constant at approximately $21 \mathrm{~N}(73 \pm 19 \mathrm{MPa})$ for SRC-PEEK-lined samples and $16 \mathrm{~N}(209 \pm 41 \mathrm{MPa})$ for control samples. Different contact stresses arose as a result of the true contact area developed for each case. The contact area was larger for SRC-PEEK sample than metalon-metal samples as a result of differences in mechanical properties between the materials, and although efforts were made to compensate for this by adjusting the normal load, the resulting contact stresses were not easily controlled, resulting in the reported differences. Initially, each sample was held at $-0.05 \mathrm{~V}$ versus $\mathrm{Ag} / \mathrm{AgCl}$, and after a 5-minute equilibration period, 120 seconds of fretting was performed followed by 60 seconds of recovery before stepping to the next voltage. This was repeated at potentials of $0 \mathrm{~V}, 0.1 \mathrm{~V}$, $0.2 \mathrm{~V}, 0.3 \mathrm{~V}, 0.4 \mathrm{~V}$, and $0.5 \mathrm{~V}$ versus $\mathrm{Ag} / \mathrm{AgCl}$.

The most important outcome to be observed in both POD tests was the maximum average fretting current achieved during each test. This result was the primary indication of the efficacy of the SRC-PEEK as a barrier to MACC in metal-on-metal couples insulated with SRCPEEK. Second, the mechanical behavior observed during fretting was recorded to understand how the surfaces interacted with the placement of SRC-PEEK as opposed to only a metal-on-metal couple. In low loads, it is typically expected that the surfaces will slide somewhat freely past one another. As load is sequentially increased, a "partial sticking" interaction occurs, where at the initiation of displacement, the pin and disk (or pin, disk, and SRCPEEK gasket) may not begin to translate until the tangential load becomes sufficiently high to overcome the static frictional interaction arising from increased asperityasperity contact. Finally, as the load increases to even higher levels, the tangential load may never reach a sufficient level to allow for the surfaces to translate past one another and instead result in a "full sticking" regime, whereby the pin simply rocks back and forth in its fixture as a result of the combination of system compliance and the high degree of asperity-asperity interaction. Average sliding coefficient of friction (COF) for control and SRCPEEK samples was calculated from the sliding portion, or horizontal section, of the tangential stress versus displacement plots. The differences in these behaviors for metal-on-metal samples as compared with SRC-PEEK gasket samples are important to understand as a means of assessing the sliding mechanics of the newly introduced material and the implications that such results may have for future modular taper applications.

After testing, the pins, disks, and SRC-PEEK samples were observed with digital optical microscopy (DOM) (Hirox, NJ, USA), secondary and backscattered scanning electron microscopy (Jeol, Peabody, MA, USA), and energy dispersive spectroscopy (EDS) (Princeton Gammatech, Princeton, NJ, USA). Microscopy was aimed at observing any surface damage arising from fretting, and EDS was used to identify possible material transfer of Ti6Al4V from the pin or CoCrMo from the disk to the SRC-PEEK surface during testing. Peaks of titanium, aluminum, vanadium, cobalt, chromium, or molybdenum found on the SRC surface would all indicate that some material transfer had occurred. Backscattered imaging techniques were used to help identify potential alloy particles to be probed using EDS. DOM was also used to calculate the true area of contact from observable damage of the pins, disks, and SRC-PEEK samples after testing. The areas calculated were used in all calculations of contact stresses arising during either of the two tests described.

\section{Statistics}

One-way analysis of variance with Student-NeumanKeuls post hoc analyses was performed on all microstructural parameters calculated from WAXS to determine if there were differences in crystallinity, crystal size, and orientation among SRC-PEEK, bulk PEEK, and PEEK fibers $(p<0.05)$. The same statistical tests were used to evaluate differences in modulus, tensile strength, yield stress, and strain to failure. Student's t-test was used in determining significant differences between maximum average fretting current densities detected $(\mathrm{p}<0.05)$. Sigmaplot (Systat, San Jose, CA, USA) was used for all statistical analyses performed in this work.

\section{Results}

With regard to thermal behavior, SRC-PEEK was found to have the highest melt temperature, followed by PEEK fibers, and then by bulk PEEK showing the lowest melt temperature (Fig. 3A). PEEK fibers show an exothermic peak at $\sim 163^{\circ} \mathrm{C}$, which indicates crystallization occurring 

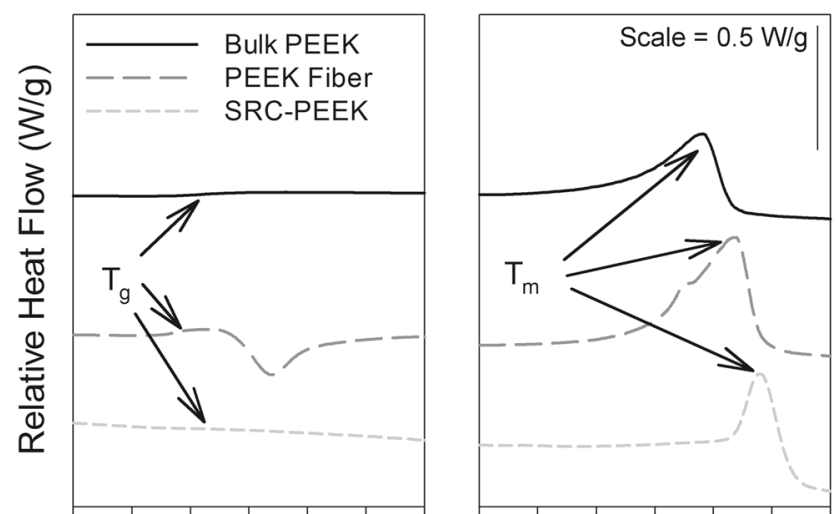

130140150160170180190300310320330340350360

A

Temperature $\left({ }^{\circ} \mathrm{C}\right)$

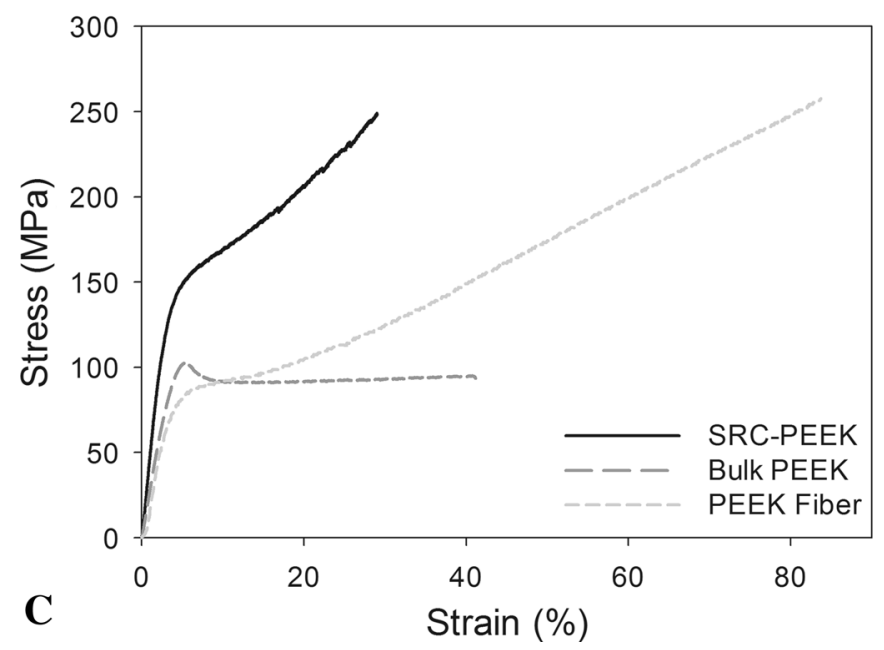

Fig. 3A-C (A) These are representative DSC traces of bulk PEEK, PEEK fiber, and SRC-PEEK highlighting temperature ranges of $T_{g}$ and $T_{m}$ (see arrows). $T_{m}$ is highest for SRC-PEEK, and the subtle $T_{g}$ indicates higher degree of crystallinity than fibers. (B) These are representative I versus $2 \theta$ scans for bulk PEEK, PEEK fiber, and

just above $\mathrm{T}_{\mathrm{g}}$, or "cold crystallization." $\mathrm{T}_{\mathrm{g}}$ was difficult to discern for bulk PEEK and SRC-PEEK as a result of its subtle presence in both cases, but was estimated to be approximately $152^{\circ} \mathrm{C}$ for both, and clearly higher than the PEEK fiber case, which had a $\mathrm{T}_{\mathrm{g}}$ of approximately $147^{\circ} \mathrm{C}$. $\mathrm{T}_{\mathrm{m}}$ was highest for SRC-PEEK $\left(347^{\circ} \mathrm{C}\right)$, and the melt endotherm was narrower than that of the PEEK fibers or the bulk, indicating that the crystallite size of the compacted SRC-PEEK may be more uniform than the others. WAXS diffraction patterns show crystallinity was highest in SRC-PEEK ( $p=0.039$ ) at $44 \%$ compared with $40 \%$ and 28\% in bulk PEEK and PEEK fibers, respectively (Fig. 3 B). Crystal size in SRC-PEEK was comparable with the bulk, whereas the increased orientation observed in PEEK fibers was comparable to the resulting SRC-PEEK composite. That is, the calculated Hermanns orientation parameter was similar between PEEK fibers and SRC-

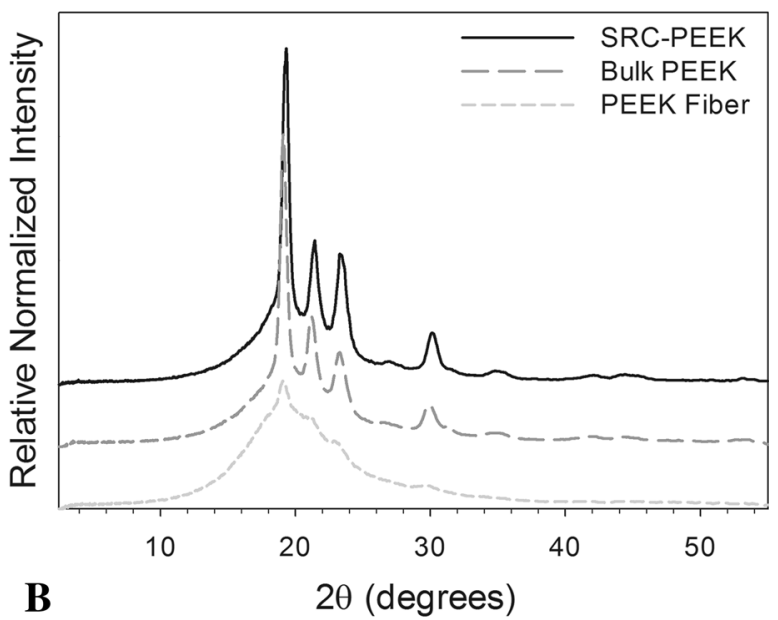

SRC-PEEK. Increased peak intensity for the bulk and SRC-PEEK are consistent with DSC findings. (C) These are representative stressstrain plots for the same three groups. Clear differences exist in mechanical behavior between groups with SRC-PEEK having the highest yield strength.

PEEK by way of analysis of variance with Student-Neuman-Keuls post hoc analysis $(0.76 \pm 0.04$ versus $0.71 \pm$ 0.15 , respectively, $\mathrm{p}=0.727$ ).

Stress-strain plots from tensile testing show clear differences in mechanical behavior with PEEK fibers showing deformation behavior that was intermediate between bulk PEEK and SRC-PEEK and SRC-PEEK notably absent of any necking type behavior, which is interesting considering its constitution of PEEK fiber reinforcement combined with the unoriented and recrystallized matrix of PEEK derived from those original fibers (Fig. 3C). SRC-PEEK had a higher modulus $(5.0 \pm 0.27$ versus $2.8 \pm 0.08 \mathrm{GPa}$, $\mathrm{p}$ $<0.001)$, strength $(217 \pm 36$ versus $99 \pm 3 \mathrm{MPa}, \mathrm{p}=$ $0.002)$, and yield stress than bulk PEEK $(138 \pm 12$ versus $99 \pm 3 \mathrm{MPa}, \mathrm{p}=0.002$; Table 1). Strain to failure was similar for SRC-PEEK and bulk PEEK $(26 \% \pm 3 \%$ versus $39 \% \pm 20 \%, \mathrm{p}=0.317)$. 
Table 1. Compilation of structural and mechanical properties for bulk PEEK, PEEK fiber, and SRC-PEEK for $n=3$ samples

\begin{tabular}{|c|c|c|c|c|c|c|c|}
\hline \multirow[b]{2}{*}{ Parameter } & \multirow{2}{*}{$\begin{array}{l}\text { Bulk PEEK } \\
(\mathrm{n}=3) \\
\text { Mean (SD) }\end{array}$} & \multicolumn{3}{|c|}{ PEEK fiber $(n=3)$} & \multicolumn{3}{|c|}{ SRC-PEEK $(n=3)$} \\
\hline & & Mean (SD) & $\begin{array}{l}\text { Mean difference versus } \\
\text { Group } 1(95 \% \mathrm{CI})\end{array}$ & $\begin{array}{l}\mathrm{p} \text { value for } 2 \\
\text { versus } 1\end{array}$ & Mean (SD) & $\begin{array}{l}\text { Mean difference versus } \\
\text { Group } 1(95 \% \mathrm{CI})\end{array}$ & $\begin{array}{l}\mathrm{p} \text { value for } 3 \\
\text { versus } 1\end{array}$ \\
\hline \multicolumn{8}{|l|}{$\begin{array}{l}\text { Microstructural } \\
\text { properties }\end{array}$} \\
\hline $\begin{array}{l}\text { Crystallinity } \\
(\%)\end{array}$ & $40(1)$ & $28(2)$ & $12(4)$ & 0.001 & $44(3)$ & $4(5)$ & 0.039 \\
\hline $\begin{array}{l}\text { Crystal size } \\
\left(\mathrm{L}_{[110]}\right)(\AA)\end{array}$ & $162(0)$ & 70 (39) & $88(63)$ & 0.01 & $156(20)$ & $6(32)$ & 0.006 \\
\hline $\begin{array}{l}\text { Orientation } \\
\quad\left(\mathrm{S}_{[200]}\right)\end{array}$ & $0.15(0.29)$ & $0.76(0.04)$ & $0.61(0.47)$ & 0.014 & $0.71(0.15)$ & $0.56(.52)$ & 0.009 \\
\hline \multicolumn{8}{|l|}{$\begin{array}{l}\text { Mechanical } \\
\text { properties }\end{array}$} \\
\hline Modulus (GPa) & $2.8(0.1)$ & $2.2(0.1)$ & $0.59(0.23)$ & 0.005 & $5.0(0.3)$ & $2.2(0.51)$ & $<0.001$ \\
\hline $\begin{array}{l}\text { Tensile strength } \\
\text { (MPa) }\end{array}$ & $99(3)$ & $195(9.5)$ & $95.8(16)$ & 0.002 & $217(36)$ & $117(58)$ & 0.002 \\
\hline $\begin{array}{l}\text { Yield stress } \\
\qquad(\mathrm{MPa})\end{array}$ & $99(3)$ & $52(11)$ & 47 (18) & 0.001 & $138(12)$ & $39(20)$ & 0.002 \\
\hline $\begin{array}{l}\text { Strain to failure } \\
(\%)\end{array}$ & $39(20)$ & $67(16)$ & $28(41)$ & 0.061 & $26(3)$ & $13(32)$ & 0.317 \\
\hline
\end{tabular}

Values are mean $\pm \mathrm{SD}$; SRC-PEEK has the highest crystallinity $(\mathrm{p}<0.05)$, with comparable crystal size to bulk PEEK and comparable orientation to PEEK fibers; SRC-PEEK has the highest modulus, tensile strength, and yield stress $(\mathrm{p}<0.05)$ and comparable strain to failure as both PEEK fibers and bulk PEEK.

The variable load (Fig. 4A) and variable voltage POD tests (Fig. 4B) along with representative fretting current versus time data for both control and SRC-PEEK-lined couples at the standard $-0.05 \mathrm{~V}$ and at $+0.5 \mathrm{~V}$ versus $\mathrm{Ag} /$ $\mathrm{AgCl}$ (Fig. 4C) showed clear differences in the current produced. In all examples, the maximum fretting current detected at any point in testing for SRC-PEEK-lined POD samples was lower than metal-on-metal controls, whether through a range of increasing contact stresses $(4.0 \mathrm{E}-5 \pm$ $3.8 \mathrm{E}-5 \mu \mathrm{A}$ versus $2.9 \mathrm{E}-3 \pm 7.1 \mathrm{E}-4 \mu \mathrm{A}, \mathrm{p}=0.018$ ) or increasingly anodic potentials $(7.6 \mathrm{E}-6 \pm 4.7 \mathrm{E}-6 \mu \mathrm{A}$ versus $1.4 \mathrm{E}-3 \pm 1.4 \mathrm{E}-4 \mu \mathrm{A}, \mathrm{p}=0.022$; Fig. 5). It should be stressed that SRC-PEEK samples did allow for some discernable rise in current over baseline (Fig. 4C); however, in all tests, this difference was generally within an order of magnitude above the level of noise in the system and always less than fretting currents detected for control samples, as indicated previously. Representative mechanical data for SRC-PEEK lined samples and control samples during the two tests performed were an important assessment of the mechanical behavior of SRC-PEEK gasket samples as compared with control samples. "Fretting loop" or tangential force versus pin displacement during the variable load test showed that sliding was similar throughout the test for each sample (Fig. 6A-B). However, the main difference seen in the SRC-PEEK samples
(Fig. 6A) was that they never reached the full stick regime as the control samples did, but rather exhibited some pin displacement even at high loads. Average COF for SRCPEEK and control samples (Fig. 6E) taken over all data collected across all loads tested were $0.16 \pm 0.03$ and 0.30 \pm 0.02 , respectively $(p=0.004)$. Similar results were seen for the variable potential test (Fig. 6C-D). Fretting loop data were similar between SRC-PEEK and control samples and similar over the range of voltages for each and were not affected by voltage. Here, however, sliding COF (Fig. 6F) was similar between SRC-PEEK and control samples during the course of this test with average COF values of $0.18 \pm 0.05$ and $0.20 \pm 0.04$, respectively $(\mathrm{p}=$ $0.529)$.

Optical images of the control disk (Fig. 7A) and the pin side of the SRC-PEEK (Fig. 7B) showed some minor damage. Minimal wear is visible on the SRC surface after testing, and there is minor discoloration visible on the pin and disk surfaces, but original polishing lines are still visible indicating very little actual wear of those surfaces. To contrast that, the control pin and disk surface (Fig. 7CD) showed visible damage and more intense discoloration, reflecting the higher amount of abrasion and higher fretting currents developed during control tests. A backscattered scanning electron micrograph (Fig. 8A) highlights the control pin, showing accumulation of damage and oxide. 

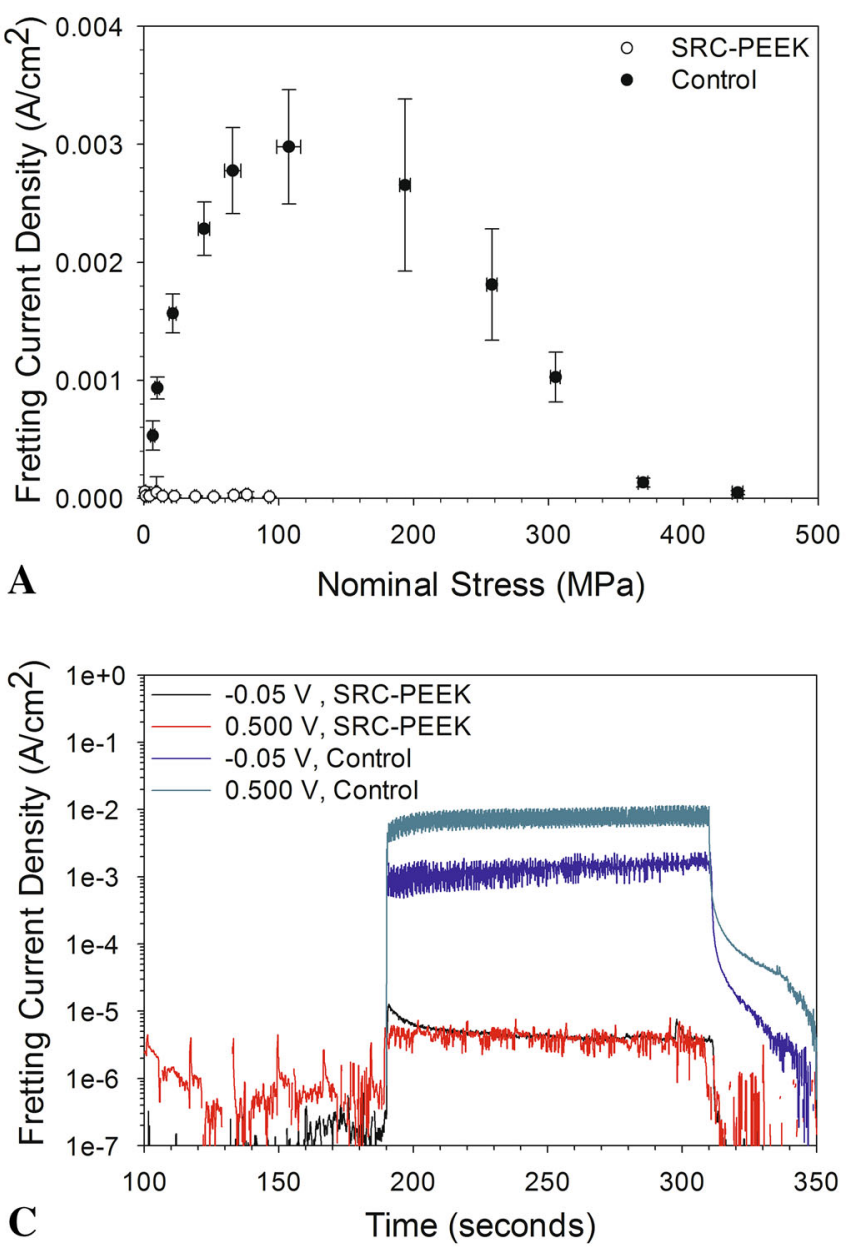

Fig. 4A-C (A) This graph represents fretting current density versus nominal stress for SRC-PEEK and control Ti6Al4V/CoCrMo pin/disk samples. Differences in modulus between PEEK and alloy surfaces resulted in large differences in contact stresses for the same loads applied. Averages are of the current density at each load condition (therefore resulting in some variation in contact stress attributable to individual contact area differences) for $\mathrm{n}=3$ samples with error bars representing $\pm 1 \mathrm{SD}$. (B) This graph represents fretting current density versus potential for SRC-PEEK and control samples.

Imaging of SRC surfaces after testing in secondary mode highlight topography (Fig. 8B), showing no severe damage to the surface, but rather more of a polishing effect. The original topography of the SRC is slightly rough after compaction, but that has been smoothed by contact with the pin. It does not appear that there has been substantive material removal but that the surface has simply plastically deformed in response to fretting motion against the pin. EDS spectra for the disk surface show typical CoCrMo peaks and two locations on the SRC surface show a location on the SRC where no alloy was detected and another location where alloy particles were detected at higher magnification (Fig. 9). The SRC spectra are paired with scanning electron microscopy images of the locations probed with EDS. The spectrum taken at low magnification

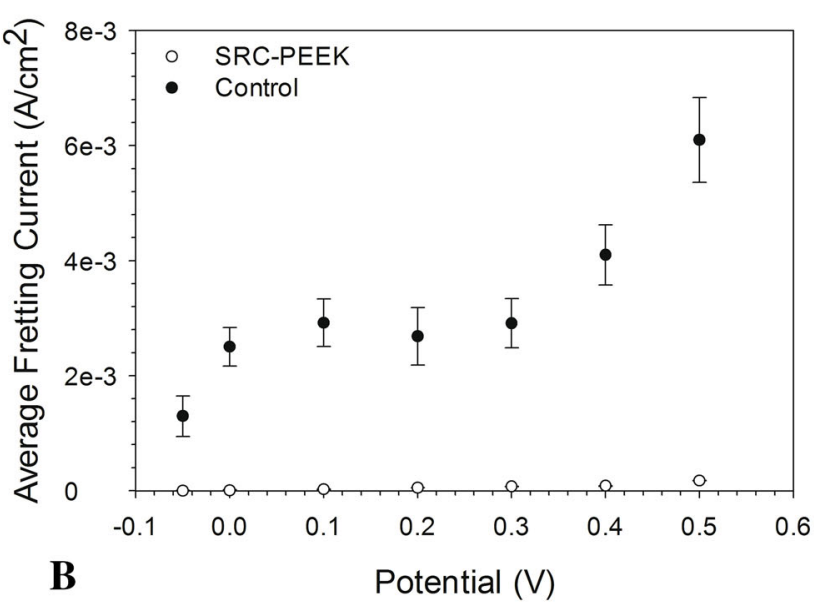

Averages are of current density at each voltage condition for $\mathrm{n}=3$ samples with error bars representing \pm 1 SD. (C) This graph represents real-time fretting current density recorded at both $-0.05 \mathrm{~V}$ and $+0.5 \mathrm{~V}$ for representative individual SRC-PEEK and control samples (beginning at 100 seconds to cutout time for current equilibration), highlighting the difference in magnitude of fretting currents between SRC-insulated and metal-on-metal control samples. Note the lack of increase in currents above the baseline for both SRCPEEK experiments.

shows no evidence of alloy or oxide on the SRC surface, but higher magnification probing yielded a result indicating that some CoCrMo material had been transferred to the SRC surface. Evidence of Ti6Al4V was not found from surfaces that had interacted with the pin.

\section{Discussion}

The use of modularity in orthopaedic implants is an important design feature. Despite the many benefits that it affords, one of the primary limitations of the design is the potential for MACC. As such, materials that can augment modular designs with the intent of limiting or preventing the onset of MACC may have potential as an important 


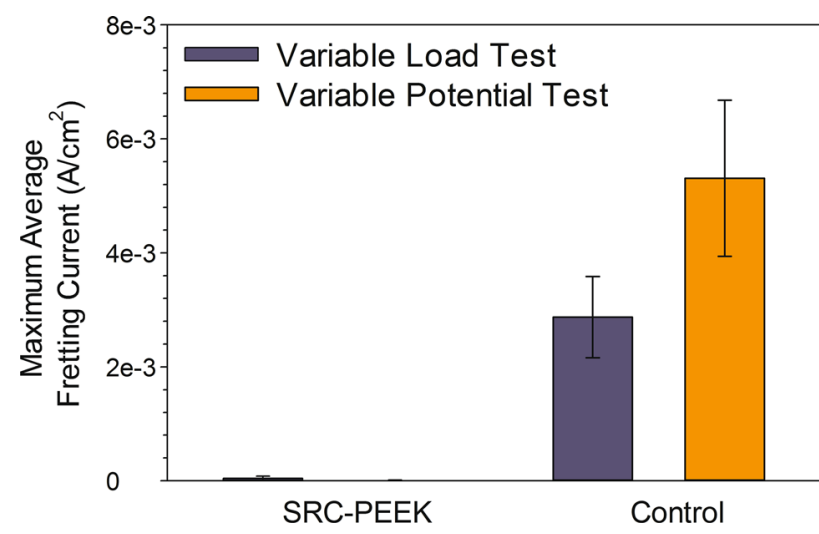

Fig. 5 This graph depicts the maximum average current density (for any given load or potential step) recorded for SRC-PEEK and control samples during variable load and variable potential tests. SRCinsulated samples developed lower current densities (virtually unchanged from the baseline current densities) than control samples in both load and potential testing for $\mathrm{n}=3$ samples $(\mathrm{p}=0.018$ and $\mathrm{p}=$ 0.022 for load and potential tests, respectively).

improvement to many current implants. This study has introduced a newly developed material, thin-film SRCPEEK, which is intended to perform in such a manner. The main goals of this study were to elucidate the thermal, structural, and mechanical properties of a new thin-film SRC-PEEK material and to explore its potential as a material to inhibit fretting corrosion processes commonly observed with popular biomedical alloys. This study has shown that hot compaction of PEEK fibers results in a material that has higher crystallinity than typical isotropic PEEK and also retains a similar degree of crystalline orientation as the fibers. This indicates that the processing method performs in the intended manner with selective melting of the fiber phase and recrystallization of the partial melt to form a coherent matrix. SRC-PEEK showed higher mechanical properties compared with bulk PEEK achieved through structural enhancement in the fiber spinning and hot compaction processes. SRC-PEEK reduced fretting current densities when fitted between alloy pin and disk couples as compared with metal-on-metal controls.

The main limitation in this study is that the manner in which fretting behavior was explored is an initial in vitro test method, aimed at providing a preliminary assessment of the electrochemical performance of SRC-PEEK. POD testing provides a good means of understanding fundamental electrochemical behavior of materials when undergoing small-scale cyclic motions, but it is a very controlled scenario that does not simulate all of the complex variables potentially at play in modular hip implants. Surgical factors such as seating of the head, angular mismatch of tapers, and others may impact the performance of these gaskets. As a result of the small nature of the samples and difficulty of the setup, it may not produce cyclic motion in the direction intended (ie, motion along the long axis of the fiber reinforcements of the SRC-PEEK samples should they become disoriented during placement). However, as a means of providing an initial short-term and fundamental understanding of the electrochemical behavior and sliding mechanics, the POD system provides a useful platform.

The thermal properties reported in this study demonstrated differences among the different forms of PEEK evaluated. SRC-PEEK had the highest melting temperature and least clearly defined glass transition, which is likely a result of hot compaction. The elevated temperature that the SRC-PEEK was processed at induced partial melting of the fiber surface and subsequent recrystallization on cooling. However, as a result of the extended time the fibers sat above their glass transition, there was also sufficient chain mobility to allow for crystallization of the fiber fraction that remained solid throughout processing, resulting in a highly uniform crystalline fraction, which also achieved the highest melt temperature. PEEK fibers and bulk PEEK both had lower melt temperatures than SRC-PEEK. PEEK fibers actually experienced crystallization just above the glass transition temperature (described as "cold crystallization") on first heating in the DSC and indicate that the initial fibers were highly amorphous. Because of this, crystallinity calculations were not thought to be reliable from DSC techniques, and x-ray diffraction techniques were used as the preferred method for calculation of all microstructural parameters. The microstructure of the SRC-PEEK was compared, using WAXS, with bulk PEEK and with the PEEK fibers and showed that processing affected crystallinity, crystallite size, and orientation, all of which were highest for SRC-PEEK. It is well known that increasing crystallinity and orientation in polymeric materials will increase ultimate mechanical properties such as modulus, strength, and yield stress, which is desirable in modular taper applications. Having fibers oriented axially to the taper should result in high-strength thin films best able to withstand the contact stresses and shear stresses associated with a fretting interface.

The SRC-PEEK material demonstrated higher modulus, strength, and yield stress than bulk PEEK. The use of a bulk polymer with lesser ultimate properties might not be able to withstand a high stress application such as the proposed modular taper gaskets. It was hypothesized that a high-strength self-reinforced composite produced from PEEK fibers would yield a material that could be incorporated into a high stress interface undergoing fretting without failing or otherwise wearing through to expose the two metal surfaces it was intended to insulate. It is interesting to note that the SRC-PEEK had higher mechanical properties than the PEEK fibers from which it was 

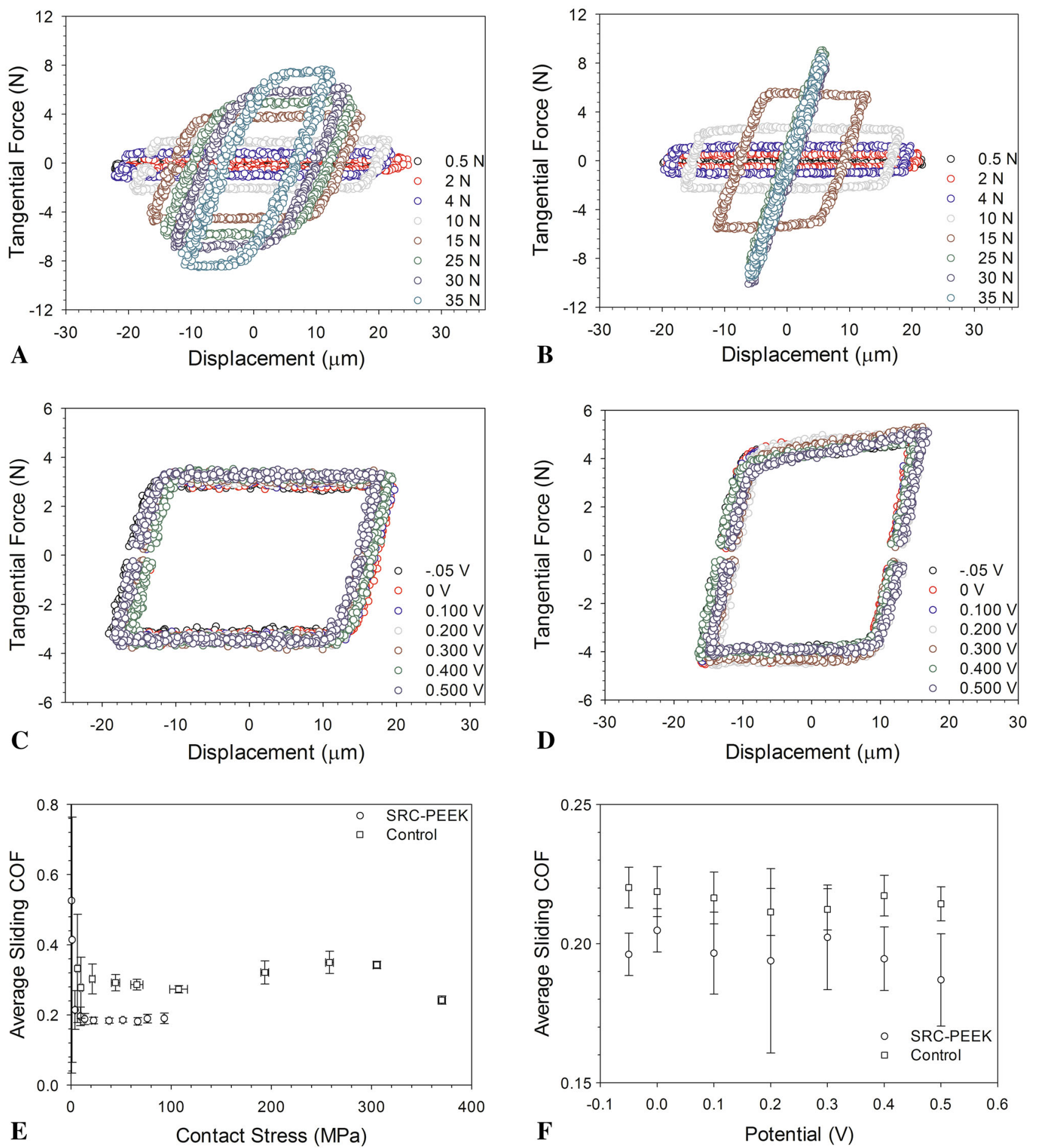

processed and higher than the bulk material. This suggests, and is confirmed by WAXS, that there is some cold crystallization occurring in the fiber phase during hot compaction that was unable to occur during the initial spinning as a result of vitrification. The increased orientation seen in the fibers, accompanied by an increase in oriented crystalline fraction in the fibers on processing, is

believed to be the reason that increased modulus, strength, and yield stress were all seen in the SRC-PEEK.

Pin-on-disk testing demonstrated that SRC-PEEK was capable of preventing fretting currents from arising over a variety of loads and a variety of potentials, which are known to be achievable for alloys in vivo [10]. One of the primary aims of the testing was to determine if the material 
4Fig. 6A-F (A) Fretting loop plots (tangential force versus pin displacement) are shown for Ti6Al4V/SRC-PEEK/CoCrMo pin/ SRC/disk configuration during variable load testing. (B) This graph represents fretting loop plot for Ti6Al4V/CoCrMo pin/disk control configuration during variable load testing. (C) This graphs represents fretting loop plot for Ti6Al4V/SRC-PEEK/CoCrMo pin/SRC/disk configuration during variable potential testing. (D) This graph represents fretting loop plot for Ti6Al4V/CoCrMo pin/disk control configuration during variable potential testing. (E) This graph depicts average COF versus nominal stress for control and SRC interfaces, representing the average of $n=3$ samples for each group with error bars denoting $\pm 1 \mathrm{SD}$. (F) This graphs represents average COF versus potential for control and SRC surfaces, representing the average of $n$ $=3$ samples taken at each individual condition of the test with error bars denoting \pm 1 SD. All samples experience similar forcedisplacement behavior during all tests with the exception that control interfaces experience full sticking between the pin and disk (correlating to electrochemical data above) at the highest loads, whereas SRC interfaces never fully reach the stick condition, exhibiting stickslip behavior in the range of loads tested. COF averaged over the entire test (barring low loads resulting from unreliable resolution of the load cell) showed that COF of the SRC surface was less than the control during variable load tests $(\mathrm{p}<0.05)$ but that no difference existed between the COF of the interfaces during variable potential testing. could withstand the mechanical environment it was subjected to and maintain its insulation of the alloy surfaces through a range of contact stresses. In the relatively shortterm testing performed, the SRC-PEEK withstood the highest contact loads $(35 \mathrm{~N})$ that could be achieved with the system, resulting in nominal stresses as high as 117 $\mathrm{MPa}$, which are on the same order of magnitude as might be expected in a modular taper junction [9]. It is important to note that the nominal contact stresses were less for SRCPEEK because it has a lower modulus than either Ti6Al4V or CoCrMo and therefore gave rise to greater contact area, whereas in metal-on-metal contact, the nominal area of fretting was more focal and much smaller thereby increasing the contact stresses. It is notable that the COF of the SRC-PEEK interface was within approximately $30 \%$ that of the metal-on-metal control samples during variable load testing. In the variable potential test that immediately followed, where COF was calculated from uniform load conditions, no differences were found between SRC-PEEK samples and metal-on-metal samples. COF is an important
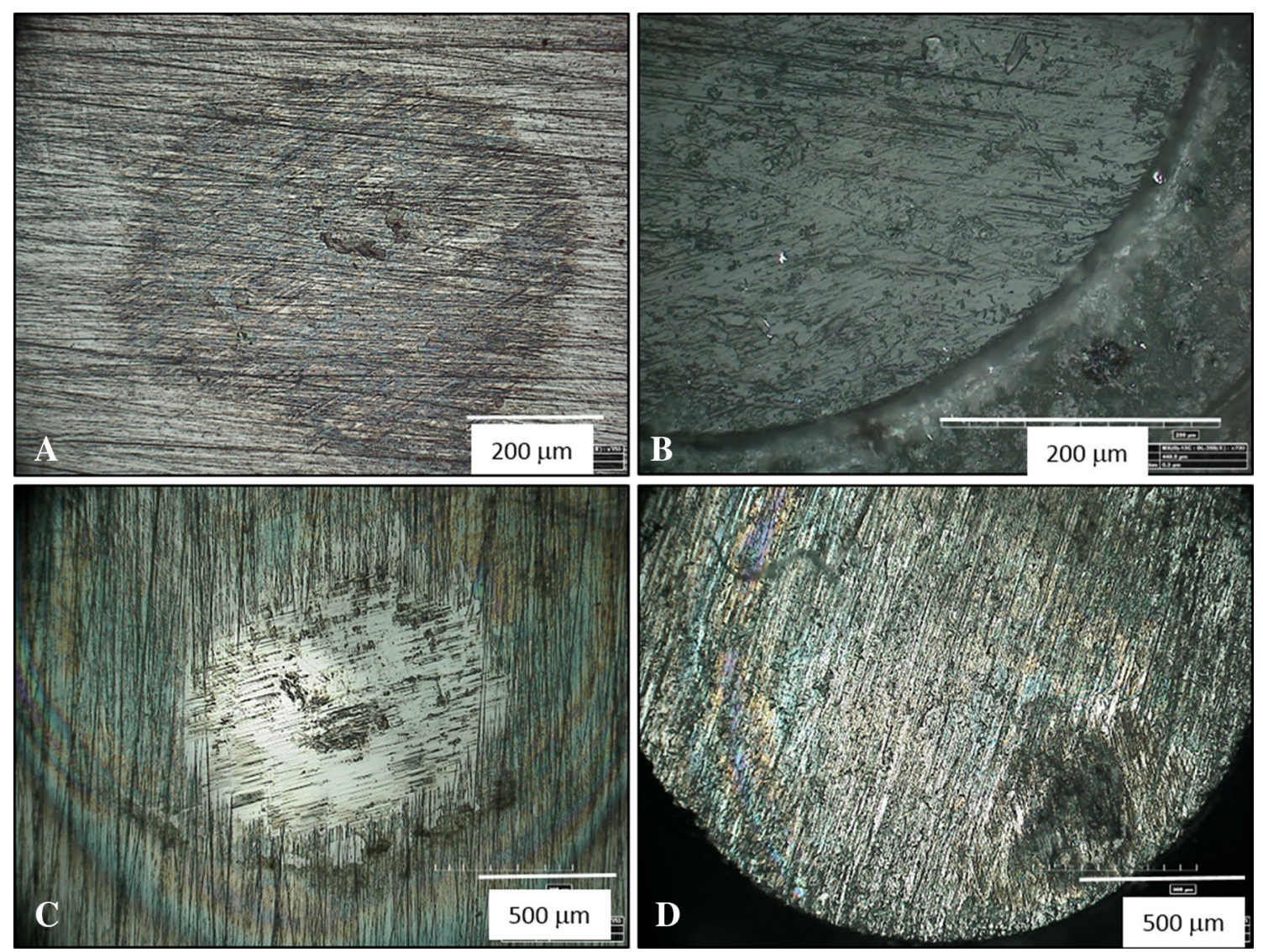

Fig. 7A-D (A) This image depicts the SRC-insulated disk after testing. Some discoloration is present, but original polishing lines are still clearly visible, indicating little damage to the surface. (B) This image depicts the SRC sample after testing. Depending on system assembly, sometimes the edge of the pin may "dig" into the SRC sample (C) This image depicts the control disk after load and

potential testing. More damage from the pin can be seen than in the case that had been fitted with SRC-PEEK and clear rings of discoloration to the surface as a result of higher fretting currents. (D) This image depicts the control pin after testing. Similar results seen as with the pin with oxide buildup in the lower right-hand corner of the image. 


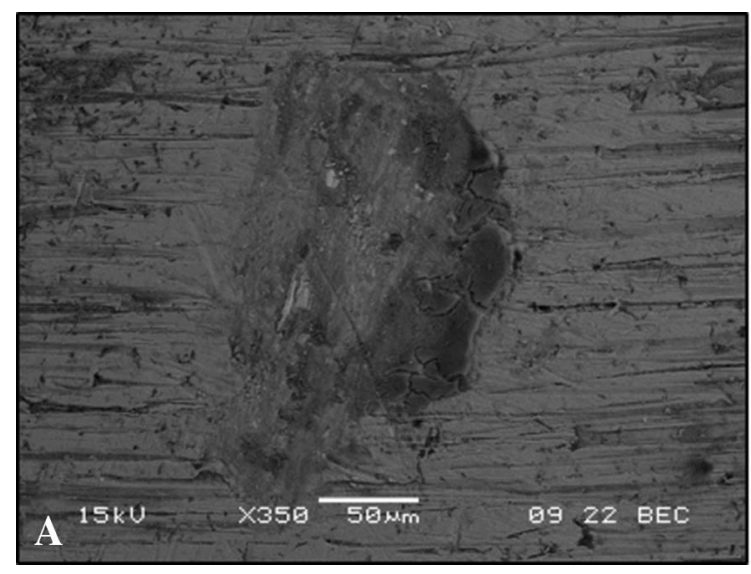

Fig. 8A-B (A) This is a closeup backscattered image of corrosion damage from control pin after testing. (B) This is a secondary image (to highlight the change in topography in the area that had

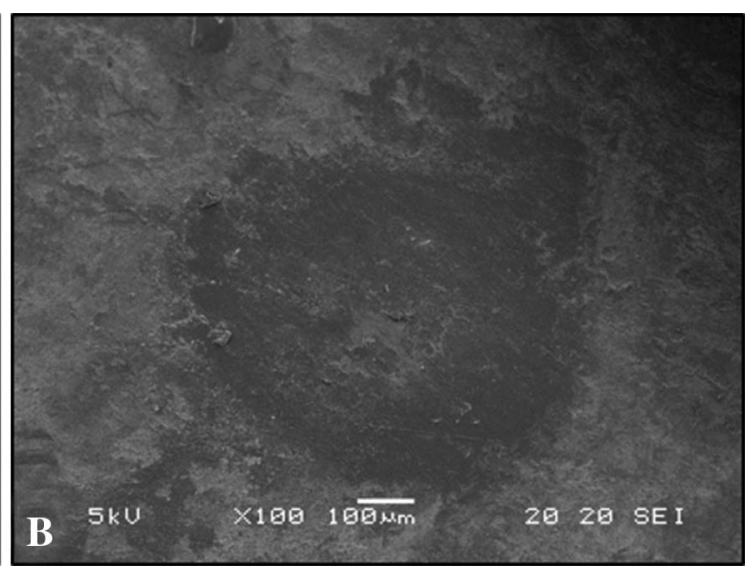

experienced fretting against the pin as compared to virgin surface) of SRC surfaces after testing.

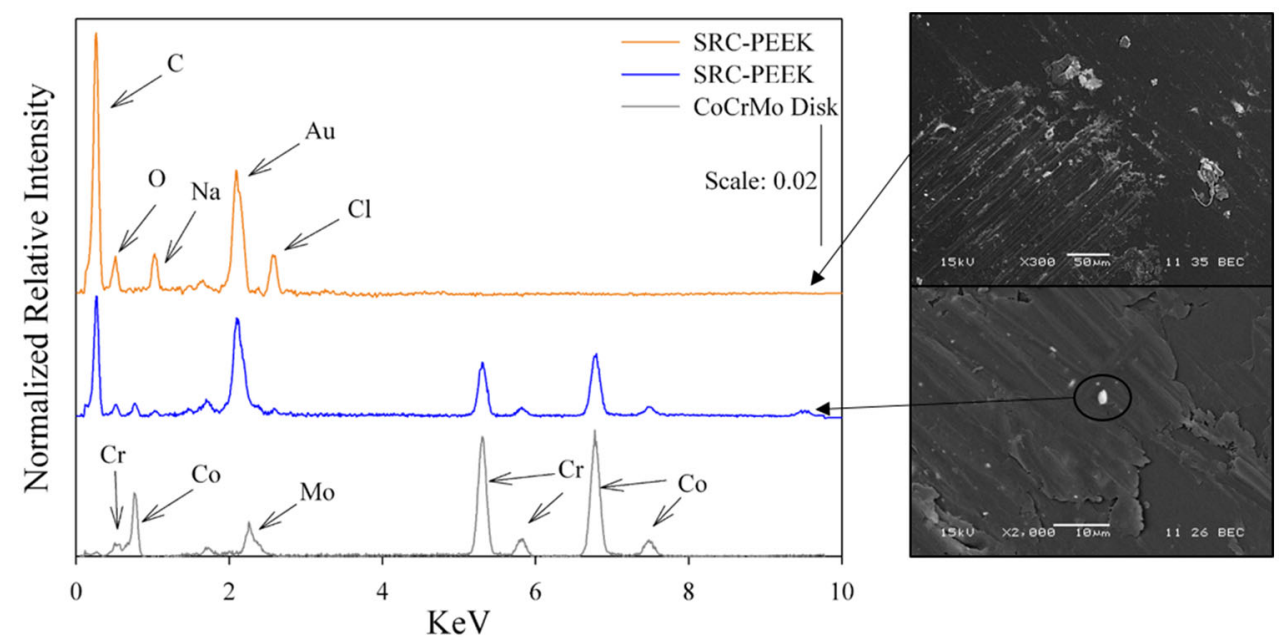

Fig. 9 This graph shows EDS spectra from two different SRC locations and one SRC-insulated disk location. The top spectrum corresponds to the scanning electron microscopy (SEM) image at the top and shows no evidence of alloy on the surface. However, the middle spectrum, taken at a high magnification on the light area

factor in determining the locking mechanics of a modular taper. It would be desirable for any material residing between the trunnion and taper to possess as near as possible the same COF to ensure secure engagement of the taper. Although this requirement is not something that was directly tested in these experiments, the result presented here yields insight into potential performance of these gaskets in actual taper geometries and loading.

Of particular interest were the images of the alloy and SRC-PEEK surfaces after testing. These images show that the SRC-PEEK inhibited abrasion of the alloy surfaces, which corresponds well to the electrochemical data showing essentially zero fretting current throughout both tests. On the SRC surface, DOM imaging shows some circled on the bottom SEM image, showed that the particle sampled was indeed CoCrMo debris from the disk as the peaks identified on the bottom spectrum taken from the CoCrMo disk indicate. This suggests that there may be some material transfer and wear of alloy despite the compliant nature of the SRC surface.

deformation from the pin interaction. In the case shown (Fig. 7B), a clear circular border can be seen from the edge of the pin where the pin had been canted slightly and the edge shown had dug into the surface. However, there was less evidence of abrasion than of plastic deformation, indicating that the film withstood the contact stresses and displacement well. Other instances were less severe as could be seen in the scanning electron microscopy images, which show a pin-side image of the SRC (Fig. 8B), where no appreciable damage can be seen. EDS spectra showed a few isolated instances of CoCrMo particles present on the SRC-PEEK surface (Fig. 9). It is unclear as to the origin of these particles, because there was no appreciable damage to the disk surface after testing. It is also unclear whether 
the particles were embedded into the surface or simply deposited on the surface with the potential of acting as a third body. The absence of any discernable gouging or wear tracks surrounding the particle suggests the latter. Because the origin of these particles cannot be clearly traced back to any particular site on the disk surface, it also cannot be ruled out that these particles are debris from polishing and that their influence on the experiment was negligible as suggested from electrochemical results. Although these results are from short-term testing, they suggest that there may be potential for desired performance in a long-term scenario.

For the desired end application of gaskets fitted in modular taper junctions, it is believed that a thinner gasket will perform better, because a hydrostatic stress state would exist in the bulk of the film, minimizing damage over time. Geometrically, a thinner film produced from smaller diameter fibers may provide the advantages outlined while also having less effect on factors such as head offset, minimizing the impact on an existing system.

In conclusion, a novel SRC-PEEK material was presented as a potential gasket thin-film material for modular tapers. Although there are many hurdles to overcome in the adoption of such a thin-film SRC-PEEK gasket technology, there are a number of potential advantages of this approach. First, it may be able to preserve the advantages of modular junctions for surgeons while potentially limiting the downside risks associated with mechanically assisted crevice corrosion. Second, it may provide protection for revisions where trunnions may be damaged. Placing an SRC-PEEK gasket over such surfaces may mitigate mechanically assisted crevice corrosion and may reduce the chance of continuing corrosion or damage from using a partially damaged taper. It showed potential as a material to inhibit fretting corrosion processes and should be further studied using long-term cyclic fretting corrosion testing in actual modular taper constructs.

Acknowledgments We thank Medtronic, Inc, for the supply of Ti6Al4V pins and CoCrMo disks used in this study.

\section{References}

1. Alexander LE. Degree of crystallinity in polymers. In: Burke E, Chlamers B, Kumhansl JA, eds. X-ray Diffraction Methods in Polymer Science. 1st ed. New York, NY, USA: John Wiley \& Sons; 1969:241-243.

2. Alexander LE. Preferred orientation in polymers. In: Burke E, Chalmers B, Krumhansl JA, eds. X-ray Diffraction Methods in Polymer Science. 1st ed. New York. NY, USA: John Wiley \& Sons; 1969:146-335.

3. Arnholt CM, MacDonald DW, Tohfafarosh M, Gilbert JL, Rimnac CM, Kurtz SM, Klein G, Mont MA, Parvizi J, Cates HE, Lee GC, Malkani A, Kraay M. Mechanically assisted taper corrosion in modular TKA. J Arthroplasty. 2014;29:205-208.
4. Barril S, Debaud N, Mischler S, Landolt D. A tribo-electrochemical apparatus for in vitro investigation of fretting-corrosion of metallic implant materials. Wear. 2002;252:744-754.

5. Barril S, Mischler S, Landolt D. Influence of fretting regimes on the tribocorrosion behaviour of Ti6Al4V in $0.9 \mathrm{wt} . \%$ sodium chloride solution. Wear. 2004;256:963-972.

6. Brown SA, Flemming CA, Kawalec JS, Placko HE, Vassaux C, Merritt K, Payer JH, Kraay MJ. Fretting corrosion accelerates crevice corrosion of modular hip tapers. J Appl Biomater. 1995;6:19-26.

7. Cook RB, Bolland BJRF, Wharton JA, Tilley S, Latham JM, Wood RJK. Pseudotumour formation due to tribocorrosion at the taper interface of large diameter metal on polymer modular total hip replacements. J Arthroplasty. 2013;28:1430-1436.

8. Cooper HJ, Urban RM, Wixson RL, Meneghini RM, Jacobs JJ. Adverse local tissue reaction arising from corrosion at the femoral neck-body junction in a dual-taper stem with a cobalt-chromium modular neck. J Bone Joint Surg Am. 2013;95:865-72.

9. Dyrkacz RMR, Brandt JM, Morrison JB, O’ Brien ST, Ojo OA, Turgeon TR, Wyss UP. Finite element analysis of the head-neck taper interface of modular hip prostheses. Tribol Int. 2015;91:206-213.

10. Gilbert JL. Electrochemical behavior of metals in the biological milieu. Comprehensive Biomaterials. 2011:21-48.

11. Gilbert JL, Buckley CA, Jacobs JJ. In vivo corrosion of modular hip prosthesis components in mixed and similar metal combinations. The effect of crevice, stress, motion, and alloy coupling. $J$ Biomed Mater Res. 1993;27:1533.

12. Gilbert JL, Mali S, Urban RM, Silverton CD, Jacobs JJ. In vivo oxide-induced stress corrosion cracking of Ti-6Al-4V in a neckstem modular taper: emergent behavior in a new mechanism of in vivo corrosion. J Biomed Mater Res Part B Appl Biomater. 2012;100:584-594.

13. Gilbert JL, Mehta M, Pinder B. Fretting crevice corrosion of stainless steel stem-CoCr femoral head connections: comparisons of materials, initial moisture, and offset length. J Biomed Mater Res Part B Appl Biomater. 2009;88:162-173.

14. Goldberg JR, Gilbert JL. In vitro corrosion testing of modular hip tapers. J Biomed Mater Res B Appl Biomater. 2003;64:78-93.

15. Goldberg JR, Gilbert JL, Jacobs JJ, Bauer TW, Paprosky W, Leurgans S. A multicenter retrieval study of the taper interfaces of modular hip prostheses. Clin Orthop Relat Res. 2002;401:149-161.

16. Hine PJ, Ward IM, Olley RH, Bassett DC. The hot compaction of high modulus melt-spun polyethylene fibres. J Mater Sci. 1993;28:316-324.

17. Jordan ND, Bassett DC, Olley RH, Hine PJ, Ward IM. The hot compaction behaviour of woven oriented polypropylene fibres and tapes. II. Morphology of cloths before and after compaction. Polymer (Guildf). 2003;44:1133-1143.

18. Kop AM, Keogh C, Swarts E. Proximal component modularity in THA-at what cost? An implant retrieval study. Clin Orthop Relat Res. 2012;470:1885-1894.

19. Megremis S, Duray S, Gilbert J. Self-reinforced composite polyethylene (SRC-PE): a novel material for orthopedic applications. In: Jacobs JJ, Craig T, eds. Alternative Bearing Surfaces in Total Joint Replacement, ASTM STP 1346. Fredericksburg, VA, USA: American Society for Testing and Materials; 1998:235-255.

20. Mroczkowski ML, Hertzler JS, Humphrey SM, Johnson T, Blanchard CR. Effect of impact assembly on the fretting corrosion of modular hip tapers. J Orthop Res. 2006;24:271-279.

21. Ouellette ES, Gilbert JL. Production and characterization of meltspun poly(ether ether ketone) fibers for biomedical applications. Polymer (Guildf). 2015;63:10-18.

22. Rasburn J, Hine PJ, Ward IM, Olley RH, Bassett DC, Kabeel MA. The hot compaction of polyethylene terephthalate. J Mater Sci. 1995;30:615-622. 
23. Rodrigues DC, Urban RM, Jacobs JJ, Gilbert JL. In vivo severe corrosion and hydrogen embrittlement of retrieved modular body titanium alloy hip-implants. J Biomed Mater Res Part B Appl Biomater. 2009;88:206-219.

24. Rojanapitayakorn P, Mather PT, Goldberg AJ, Weiss RA. Optically transparent self-reinforced poly(ethylene terephthalate) composites: molecular orientation and mechanical properties. Polymer (Guildf). 2005;46:761-773.

25. Swaminathan V, Gilbert JL. Fretting corrosion of CoCrMo and Ti6Al4V interfaces. Biomaterials. 2012;33:5487-5503.

26. Swaminathan V, Gilbert JL. Potential and frequency effects on fretting corrosion of Ti6Al4V and CoCrMo surfaces. J Biomed Mater Res Part A. 2013;101:2602-2612.
27. Urban RM, Gilbert JL, Jacobs JJ. Corrosion of modular titanium alloy stems in cementless hip replacement. J ASTM Int. 2005;2:1-10.

28. Ward IM. Developments in oriented polymers, 1970-2004. Plast Rubbers Compos. 2004;33:189-194.

29. Wright DD, Gilbert JL, Lautenschlager EP. The effect of processing temperature and time on the structure and fracture characteristics of self- reinforced composite poly (methyl methacrylate). J Mater Sci Mater Med. 1999;10:503-512.

30. Yan RJ, Hine PJ, Ward IM, Olley RH, Bassett DC. The hot compaction of SPECTRA gel-spun polyethylene fibre. J Mater Sci. 1997;32:4821-4831. 